\title{
The Use of Bovine Serum Protein as an Oral Support Therapy Following Coronavirus Challenge in Calves
}

\begin{abstract}
A.S. Leaflet R1910
Carrie Jaynes, Undergraduate Research Assistant, Howard Tyler, Associate Professor of Animal Science, James Quigley, III, American Protein Corporation, Ames, Iowa , Sheila Kapil, Kansas State University, Manhattan, and John Arthington, University of Florida

\section{Summary and Implications}

The objective of this experiment was to investigate the therapeutic efficacy of feeding a supplemental bovine serum protein blend to calves challenged with virulent coronavirus. Twelve Holstein bull calves were orally challenged with $1 \mathrm{x}$ $10^{7} \mathrm{PFU}$ of virulent coronavirus isolate. Infection was allowed to progress for a period of $24 \mathrm{~h}$ prior to the initiation of treatment. On d 1, treated calves began receiving $160 \mathrm{~g}$ of a blood serum protein blend (16 $\mathrm{g} \mathrm{IgG})$ mixed into milk replacer powder $(67 \mathrm{~g})$ at both the AM and PM feedings. Control calves received only milk replacer powder (227) at both feedings. Response to coronavirus challenge and dietary treatment was monitored prior to AM and PM feeding by the collection of multiple clinical measures. Fecal consistency was decreased $(\mathrm{P}<0.01)$ by coronavirus challenge, but was not affected by dietary treatment. Mean daily rectal temperature and heart rate were not affected by dietary treatment. Average packed cell volume was higher $(\mathrm{P}<0.01)$ in rreated calves compared to control (35.0 and $27.0 \%$ ). Coronavirus challenge resulted in an immediate increase in respiration rate, decreasing by $\mathrm{d}$ 7. Control calves tended to have a greater $(\mathrm{P}=0.06)$ average respiration rate compared to treated ( 28.7 vs. 26.8 breaths / min.). Treated calves had a higher $(\mathrm{P}=0.02)$ average feed intake versus control ( 0.57 vs. $0.44 \mathrm{~kg} / \mathrm{d})$. These data suggest that bovine serum supplemented milk replacer may decrease the severity of disease in young calves exposed to coronavirus. The ability of a dietary treatment to potentially alleviate symptoms of a viral enteric disease is of great importance to the dairy industry.
\end{abstract}

\section{Introduction}

Over 50 percent of dairy heifer calf mortality on U.S. dairy farms is related to diarrhea. Bovine coronavirus affects both dairy and beef and is most common in calves 1 and 2 weeks of age. The mode of infection is often via the oral route, but both enteric and respiratory $\mathrm{BCV}$ infections are common. Calf morbidity rates from naturally occurring $\mathrm{BCV}$ infection may be as high as 15 to $25 \%$. Viral infections such as BCV are not treatable with antibiotics, except to combat secondary bacterial infection. Supportive care and electrolyte therapy attempting to replace lost fluids and prevent dehydration are often the only treatments available.
Bovine serum has been shown to be an effective source of exogenous passive immunoglobulin for newborn calves. The use of bovine serum in older calves experiencing enteric challenge has received little attention. In calves challenged with Escherichia coli, calves offered bovine plasma had equal improvements in attitude, hydration, and body weight gain as calves treated with antibiotics. The objective of this study was to evaluate the effect of dietary bovine serum on dairy calf health and performance following enteric challenge with bovine coronavirus.

\section{Procedures}

The animals utilized in these experiments were cared for by acceptable practices as outlined in the Guide for the Care and Use of Agricultural Animals in Agricultural Research and Teaching (1988). Additionally, this protocol was reviewed and approved by the Iowa State University Animal Care and Use Committee (Approval \# 6-6-3245-3B) and the Biohazards and Public Health Committee (Approval \# 96-I-009-A).

Animals, Coronavirus Challenge, and Dietary Treatments

Eighteen Holstein bull calves (ave. 3 weeks of age) were housed in indoor pens at the Iowa State University Dairy Farm calf barn. Calves were screened for previous exposure to bovine coronavirus (BCV) by the examination of anti$\mathrm{BCV}$ antibody in whole blood and viral shedding in fecal samples using standard methods. Twelve calves tested negative for fecal viral shedding and antibody titer to BCV. These were selected to participate in the trial.

All calves were challenged orally on day 0 with a virulent strain of BCV known to produce moderately severe, nonfatal diarrhea.

Coronavirus was delivered orally in $10 \mathrm{~mL}$ of cell culture media using a $12 \mathrm{~mL}$ syringe connected to a length of plastic tubing held in place in the back of the oral cavity. All calves were fasted for $24 \mathrm{~h}$ following BCV challenge. After fast, calves were randomly assigned to one of two dietary treatments consisting of a control (control; $n=5$ ) and treated group (serum-fed; $n=7$ ). Control calves received 227 grams of a commercial calf milk replacer (CMR; $20 \%$ fat and $20 \%$ protein) blended into $2 \mathrm{~L}$ of warm tap water twice daily. Serum calves received 160 grams CMR, plus 67 grams of a blended commercial powder containing spraydried, bovine serum (Lifeline ${ }^{\mathrm{TM}}$ ) into $2 \mathrm{~L}$ of warm tap water, twice daily. The bovine serum product contained 10\% immunoglobulin on an as-fed basis. All liquid feed not voluntarily consumed was fed using an esophageal tube. All calves were offered one pound of a commercial, pelleted calf starter daily. Dry feed refusal was recorded daily. 


\section{Clinical measurements}

Whole blood samples, for the measure of packed cell volume (PCV) were collected once daily before the morning feeding. Objective clinical observations included rectal temperature, heart rate, and respiration rate. Subjective clinical observations were also collected, including attitude ( 1 to 3 scale) and fecal consistence score ( 1 to 4 scale) as described in Table 1. Body weights were recorded at the beginning of the study and again at d 14 following BCV challenge.

\section{Statistical analysis}

Analysis of variance was performed using the general linear model procedures of SAS (1988) using a completely randomized model. For multiple measures over time, a split-plot design was used with calf as the whole plot and time and time $\mathrm{x}$ treatment interactions in the subplot. Treatment means were compared using least significant differences with the appropriate error term.

\section{Results and Discussion}

Oral challenge of virulent bovine coronavirus resulted in a decrease in fecal consistency, which improved over the $7 \mathrm{~d}$ post-challenge data collection period (Figure 1). Dietary treatment with bovine serum did not influence fecal consistency (Table 2). Serum-fed calves tended $(\mathrm{P}=0.12)$ to be more responsive following challenge compared to control as measured by calf attitude (Table 2). Decreased attitude score for all calves reached a peak on $\mathrm{d} 3$ and improved to baseline values by d 7 (Figure 1). This improvement in calf responsiveness was reflected by a higher $(\mathrm{P}=0.02)$ total feed intake by serum-fed calves compared to control calves (Table 2). Although coronavirus challenge resulted in clinical morbidity, there were no instances of mortality for either treatment.
Calf rectal temperature tended $(\mathrm{P}=0.06)$ to be lower for serum-fed calves compared to control calves (Table 2), however, this difference was minor and probably of no biological significance. Packed cell volume is a common measure of hydration. Calves fed bovine serum had a higher $(\mathrm{P}<0.01) \mathrm{PCV}$ compared to control (Table 2). Respiration rate was greatest on $\mathrm{d} 1$ following challenge and decreased over the following $7 \mathrm{~d}$ (Figure 2). Respiration rate of serum-fed calves tended to be lower $(\mathrm{P}=0.06)$ than control calves (Table 2).

Starting and ending body weights were similar for both treatments (Table 3). Change in body weight and daily body weight gain at $14 \mathrm{~d}$ following challenge was also similar for both treatments (Table 3 ).

The bovine-serum material used in the current study was not tested for titers against bovine coronavirus. Nevertheless, coronavirus is widespread in cattle populations, suggesting that the presence of coronavirusspecific antibody titers would be likely in pooled bovine blood.

The inclusion of bovine plasma as an ingredient in calf milk replacers has been investigated. Feed intake was more closely correlated with calf gain for serum-fed calves than for control calves $\left(\mathrm{R}^{2}=0.92\right.$ and 0.65 for serum-fed and control calves, respectively) suggesting less variability in the efficiency of plasma fed calves to convert feed into added body weight.

Fortification of calf milk replacer with bovine serum appears to be an effective management approach for improving calf health during coronavirus challenge. In the current study, calves fed bovine-serum fortified calf milk replacer were more responsive, tended to have a less pronounced increase in respiration, and had greater total feed intake compared to control calves. Further investigation into the use of bovine-serum as a dietary therapeutic aid for calves experiencing enteric challenge is warranted. 
Table 1. Response criteria for subjective clinical measures. ${ }^{1}$

\begin{tabular}{lllll}
\hline & Clinical Score & & & \\
Clinical Measure & 1 & 2 & 3 & 4 \\
\hline Attitude & Responsive & Non-active & Moribund & N/A \\
Fecal score & Formed & Soft & Runny & Liquid/Watery \\
\hline
\end{tabular}

${ }^{\mathrm{T}} \mathrm{S}$ coring was conducted by a common person throughout the study.

${ }^{2} \mathrm{~N} / \mathrm{A}=$ not included in the scoring scale.

Table 2. Effect of bovine serum protein on clinical measures of Holstein calves challenged with bovine coronavirus.

\begin{tabular}{llll}
\hline Clinical measure $^{\mathrm{a}}$ & Control $^{\mathrm{b}}$ & Serum-fed $^{\mathrm{b}}$ & $\mathrm{P}=$ \\
\hline Fecal Score $(\mathrm{scale}=1-4)^{\mathrm{c}}$ & $1.61 \pm .07$ & $1.73 \pm .06$ & 0.19 \\
Attitude $(\text { scale }=1-3)^{\mathrm{c}}$ & $1.15 \pm .03$ & $1.08 \pm .03$ & 0.12 \\
Heart Rate (beats / min) & $88.1 \pm 1.2$ & $86.5 \pm 1.0$ & 0.31 \\
Rectal Temperature $\left({ }^{\circ} \mathrm{C}\right)$ & $39.0 \pm 0.1$ & $38.9 \pm 0.1$ & 0.06 \\
Respiration Rate $($ inhalations / min) & $28.7 \pm 0.7$ & $26.8 \pm 0.6$ & 0.06 \\
Packed cell volume $(\%)$ & $27.0 \pm 0.5$ & $35.0 \pm 0.4$ & $<0.001$ \\
Feed Intake $(\mathrm{kg} / \mathrm{d})$ & $0.44 \pm 0.06$ & $0.57 \pm 0.05$ & 0.02 \\
\hline
\end{tabular}

${ }^{\mathrm{a}}$ Clinical measures collected twice daily over 7 days post-challenge by a common technician.

${ }^{\mathrm{b}}$ Mean $\pm \mathrm{SE}$.

${ }^{\mathrm{c}}$ Subjective measures scored as described in Table 1.

Table 3. Effect of bovine serum protein on body weight gain of Holstein calves challenged with bovine coronavirus.

\begin{tabular}{llll}
\hline Measure $^{\mathrm{a}}$ & Control $^{\mathrm{b}}$ & Serum-fed $^{\mathrm{b}}$ & $\mathrm{P}=$ \\
\hline Start weight, kg & $45.1 \pm 1.2$ & $46.3 \pm 1.0$ & 0.46 \\
End weight, kg & $55.1 \pm 2.6$ & $55.7 \pm 2.2$ & 0.88 \\
Gain, kg & $10.1 \pm 1.8$ & $9.3 \pm 1.5$ & 0.75 \\
ADG, kg/d & $0.72 \pm 0.13$ & $0.67 \pm 0.11$ & 0.76 \\
\hline
\end{tabular}

${ }^{\mathrm{a}}$ Individual body weights were collected prior to coronavirus challenge and at d 14 after challenge.

${ }^{\mathrm{b}}$ Mean \pm SE. 


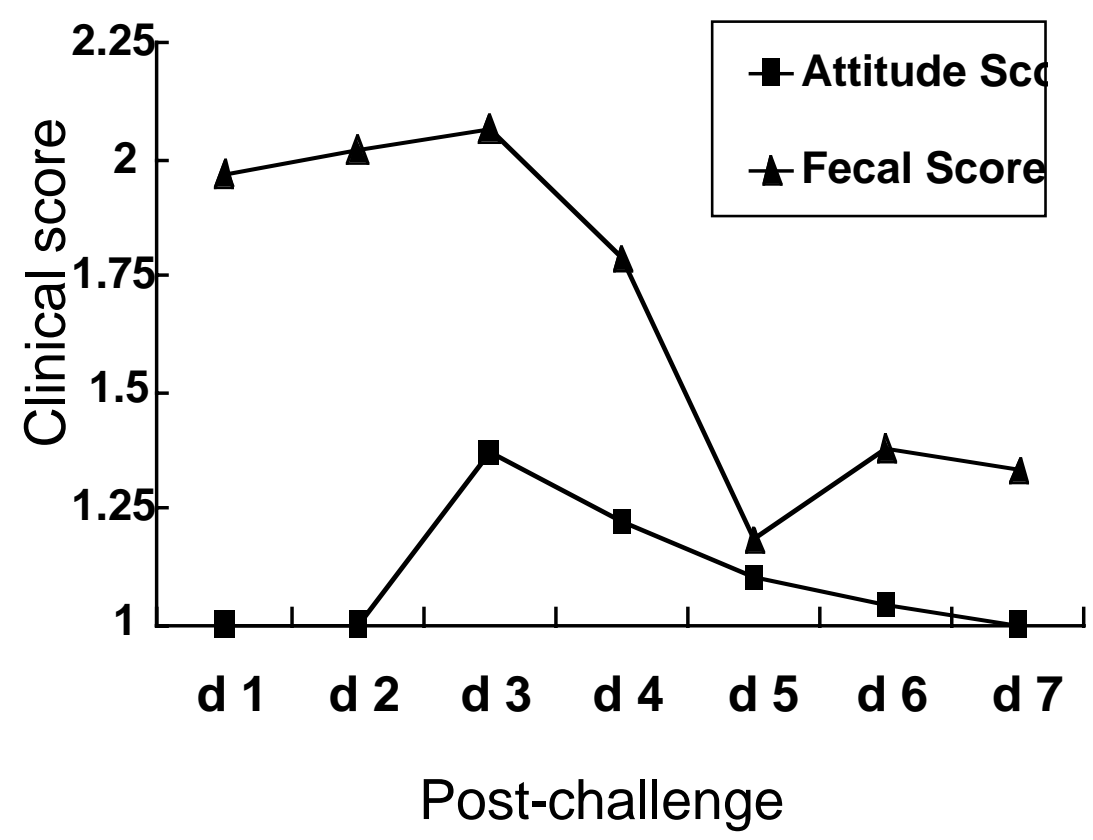

Figure 1. Attitude and fecal score of Holstein bull calves challenged with coronavirus. Measures were scored subjectively 2 times daily using a common technician. Scoring system described in Table 1. Standard error of the mean $=0.08$ and 0.21 for attitude and fecal score, respectively.

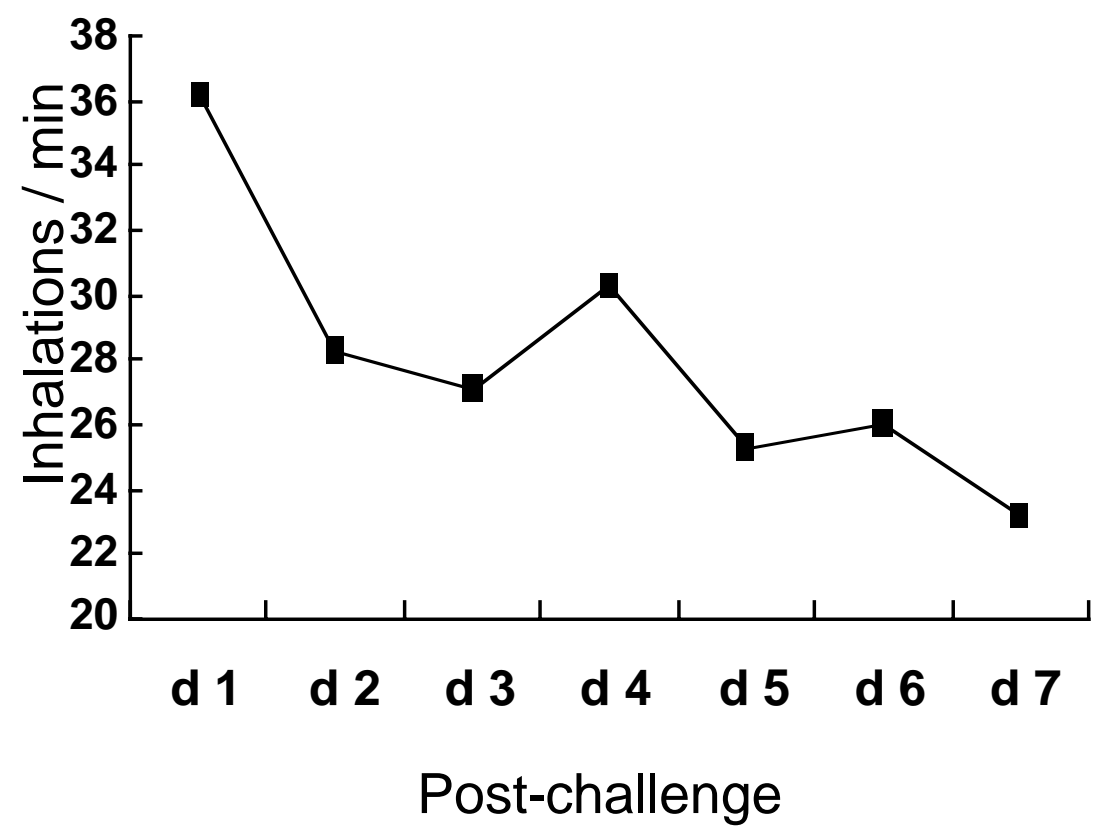

Figure 2. Respiration rate of Holstein bull calves challenged with coronavirus. Inhalations were counted by a common technician using a Litman stethoscope for $30 \mathrm{~s}$ periods. Standard error of the mean $=2.9$ inhalations / min. Effect of time, $P<0.01$. 